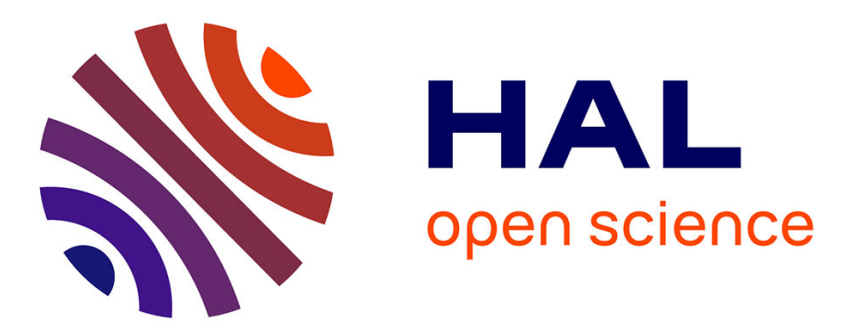

\title{
Meta-analysis of genetic association studies: magic tool or dangerous black box?
}

\author{
Cosetta Minelli, John Thompson
}

\section{To cite this version:}

Cosetta Minelli, John Thompson. Meta-analysis of genetic association studies: magic tool or dangerous black box?. European Journal of Epidemiology, 2010, 25 (11), pp.761-763. 10.1007/s10654-010-9492y . hal-00610680

\section{HAL Id: hal-00610680 \\ https://hal.science/hal-00610680}

Submitted on 23 Jul 2011

HAL is a multi-disciplinary open access archive for the deposit and dissemination of scientific research documents, whether they are published or not. The documents may come from teaching and research institutions in France or abroad, or from public or private research centers.
L'archive ouverte pluridisciplinaire HAL, est destinée au dépôt et à la diffusion de documents scientifiques de niveau recherche, publiés ou non, émanant des établissements d'enseignement et de recherche français ou étrangers, des laboratoires publics ou privés. 
Meta-analysis of genetic association studies: magic tool or dangerous black box?

Cosetta Minelli ${ }^{1}$, John Thompson ${ }^{2}$

${ }^{1}$ Institute of Genetic Medicine, EURAC research, Bolzano, Italy

${ }^{2}$ Department of Health Sciences, University of Leicester, Leicester, UK

WORD COUNT: 1,570

\section{Address for correspondence:}

Dr. Cosetta Minelli

Institute of Genetic Medicine

EURAC Research

Viale Druso 1

39100 Bolzano, Italy

Tel: +390471055 526; Fax: +390471055 599

E-mail: cosetta.minelli@eurac.edu 
In the field of genetic epidemiology, where primary studies are often underpowered to detect small genetic effects and where conflicting results and non-replication of initial findings are often encountered ${ }^{1}$, the importance of meta-analysis has been widely recognised, as demonstrated by the steep increase in the number of published genetic meta-analyses over time ${ }^{2}$. What has not received sufficient attention is the fact that the results of a meta-analysis, as with any other study design, are only valid if the meta-analysis has been conducted following appropriate methodology. Therefore, the paper by Boccia and colleagues published in this issue ${ }^{3}$, which reports the findings of a systematic review on the quality of meta-analyses of genetic association studies in the field of cancer research, represents an important contribution to a rather neglected area.

Boccia and colleagues reviewed 169 papers published up to January 2009 and report a substantial methodological improvement over time. However, such improvement seems limited to more general aspects, such as the search for articles published in different languages and the assessment of statistical heterogeneity and publication bias, while other aspects specific to genetics, such as the assessment of Hardy-Weinberg equilibrium and the justification for the choice of a genetic model, still appear to be largely overlooked. Similar findings were reported in a previous review of 120 genetic meta-analyses, randomly sampled among those published between 2005 and 2007, where methodological issues specific of genetic meta-analyses were those most neglected ${ }^{2}$. This is not surprising, given that the use of metaanalysis in genetic epidemiology is still relatively new compared with its use in other fields of medicine.

The Human Genome Epidemiology Network (HuGE Net), founded in 1998 with the aim of developing and disseminating population-based human genome information, provides some guidance on how to perform meta-analyses of genetic association studies. HuGE reviews, that is systematic reviews and metaanalyses performed in accordance with the HuGE Review Handbook ${ }^{4}$ and with their methods prespecified in a protocol submitted to HuGE Net, have shown better quality compared with the rest of published genetic meta-analyses, particularly for those methodological aspects specific to genetics ${ }^{2}$. This suggests that the positive influence of HuGE Net on the quality of genetic meta-analyses performed within its sphere has not yet extended to the broader circle of investigators working in this field. Boccia and colleagues conclude in their article that there is a need for consensus guidelines for the conduct and reporting of meta-analyses of genetic association studies. Producing and disseminating such guidelines 
may not suffice, though, and it could be argued that the most effective way of improving the quality standard of any type of research is through enforcement of stricter journal policies on the requirements for publication. The adoption of the Consolidated Standards for Reporting of Trials (CONSORT) statement by high quality journals has been shown to improve the quality of published randomised clinical trials ${ }^{5}$, with similar effects having been suggested for the Quality of Reporting of Meta-analyses (QUOROM) statement on the quality of published meta-analyses ${ }^{6}$. It is interesting that the quality of published metaanalyses of genetic association studies does not seem to be influenced by the type of publication journal (general medicine, genetics or specialty journal) or its quality (crudely approximated by its impact factor $)^{2}$, which suggests that guidance is indeed urgently needed to help journal editors achieve a quality standard for these papers similar to that of other research articles.

Guidelines for quality assessment of meta-analyses of genetic association studies could make a dramatic difference for a journal's reviewers, who are sometimes unaware of the specific methodological issues involved and their possible implications for the validity of the findings. The fact that meta-analyses published together with a genetic association study show poorer quality than meta-analyses published on their own ${ }^{2}$, suggests that people who are not familiar with this study design may sometimes see metaanalysis as a "nice addition" to a primary study, even when it is performed "quick-and-dirty". This is clearly not true and a poor quality meta-analysis may be very misleading, since it could provide biased results and misleadingly narrow confidence intervals. The development of guidelines requires good knowledge of the methods available and their assumptions, and also an appreciation of the practical problems involved in their application. Collecting empirical evidence on the quality of published metaanalyses requires a large amount of work, and yet such effort is undoubtedly worthwhile if it helps improve the quality of future meta-analyses by highlighting areas where more methodological guidance is needed. Articles such as the one by Boccia and colleagues are therefore to be welcomed.

In interpreting the findings from reviews on the quality of published meta-analyses such as the article by Boccia and colleagues, one needs to remember that quality assessment can only be based on what is reported in the paper, so that the assessor cannot disentangle quality of conduct from quality of reporting. Obviously it is the investigator's responsibility to guarantee that important information on aims, methodology and findings of the meta-analysis are clearly reported, with discussion of the assumptions 
underlying the methods and their implications on the results, but limitation of space for publication may sometimes be a constraint on reporting, particularly when a meta-analysis is published alongside a primary genetic association study, where much of the paper needs to cover methods and results of that study. In practice, however, the opportunity to post additional information on journals' websites is becoming increasing common, and even when this is not possible, investigators can often use their own institution's website. Reviewers and journal editors can play an important role in improving the transparency of the reporting of genetic meta-analyses by encouraging and facilitating the posting of detailed information on the web.

While everybody agrees on the need for more guidance in the conduct and reporting of meta-analyses of genetic association studies, we believe that a "recipe-like approach" would not be appropriate. There are ways of conducting and reporting a meta-analysis of genetic association studies that should always be discouraged, but unfortunately there is not a single recipe for producing valid results that applies in all situations. This has direct implications for the quality assessment of such meta-analyses, where no checklist can avoid the need from the assessor to critically evaluate the appropriateness of a given approach in the light of the specific scenario and aims of that meta-analysis. One example will illustrate the limitations of excessive simplification. Boccia and colleagues stress the importance of a comprehensive literature search which can identify all possible studies performed on a given topic, and they use the absence of language restriction to English as a marker of good quality. Given the increasingly large contribution of countries such as China to current genetic research, coverage of other languages is not a minor decision and could mean a substantial difference in the number of studies to be included. As Boccia and colleagues point out, language restrictions can be associated with a geographical form of publication bias, known as "language bias" or "local literature bias", whereby studies performed in a non-English speaking country are more likely to be published in international journals (in English) if their results are statistically significant, and in national journals if they are not ${ }^{7}$. However, there are situations in which comprehensiveness of the literature search may not be necessary or even desirable. For example, imagine one has performed a genetic association study and wish to conduct in parallel a systematic review and meta-analysis. There are two possible reasons for doing so: 1) the findings of the primary study are not "convincing" because of limited sample size, and the aim is to address this by pooling the study with other similar studies to increase statistical power; 2) the findings of the primary 
study are conclusive, and the aim is to evaluate whether the same association is observed across different populations, as this would suggest that the overall genetic effect is not heavily influenced by gene-gene or gene-environment interactions. It is obvious that identifying studies performed in all countries is much more important in the second scenario, where the primary aim of the meta-analysis is to assess generalisability of results and therefore the presence of between-study heterogeneity is crucial. In the first situation, where the aim is to increase statistical power, one might be better off by restricting the literature search to facilitate identification of studies performed in similar populations, in order to reduce betweenstudy heterogeneity.

In conclusion, a meta-analysis cannot be conducted as it were a black box, with data from a number of studies being fed into it and a fixed set of rules adopted to process them and provide a pooled estimate. Performing a meta-analysis requires as much methodological knowledge and experience as any other study design, and the investigator needs to understand the underlying assumptions and implications of the use of alternative methods in order to choose the appropriate one in any given situation. On the other hand, the assessor of the quality of a meta-analysis, be it the reader of a journal or the reviewer and journal editor judging the study's suitability for publication, needs to evaluate critically the appropriateness of the methods chosen in light of the stated aims of the meta-analysis. The availability of checklists for quality assessment would greatly help, but these would still need to be used with judgment. It is certainly easier to assess the quality of reporting rather than conduct, where a golden rule is to ensure that the methods and results are transparently reported. 


\section{References}

1. Colhoun HM, McKeigue PM, Davey Smith G. Problems of reporting genetic associations with complex outcomes. Lancet 2003; 361(9360):865-872

2. Minelli C, Thompson JR, Abrams KR, Thakkinstian A, Attia J. The quality of meta-analyses of genetic associations: a review with recommendations. Am J Epidemiol 2009; 170:1333-43

3. Boccia S, De Feo E, Gallì P, Gianfagna F, Amore R, Ricciardi G. A systematic review evaluating the methodological aspects of meta-analyses of genetic association studies in cancer research. Eur J Epidemiol ..........

4. Little J, Higgins JPT (editors). The HuGENet ${ }^{\mathrm{TM}}$ HuGE Review Handbook, version 1.0. http://www.hugenet.ca (accessed 28 February 2006)

5. Moher D, Jones A, Lepage L; CONSORT Group (Consolitdated Standards for Reporting of Trials). Use of the CONSORT statement and quality of reports of randomized trials: a comparative before-and-after evaluation. JAMA 2001; 285(15):1992-5

6. Delaney A, Bagshaw SM, Ferland A, Manns B, Laupland KB, Doig CJ. A systematic evaluation of the quality of meta-analyses in the critical care literature. Crit Care 2005; 9(5):R575-82

7. Pan Z, Trikalinos TA, Kavvoura FK, Lau J, Ioannidis JP. Local literature bias in genetic epidemiology: an empirical evaluation of the Chinese literature. PloS Med 2005;2:e334 